\title{
A COMPUTATIONAL STUDY OF THE STATIC AND DYNAMIC RESPONSE OF A HYBRID BARREL VAULT STRUCTURE
}

\author{
Jianguo Cai ${ }^{1}$, Yixiang $\mathrm{Xu}^{2, *}$, Fang Wang ${ }^{3}$, Jian Feng ${ }^{4, *}$ and Jin Zhang ${ }^{5}$ \\ ${ }^{1}$ Ph.D., Key Lab. of C\&PC Structures of Ministry of Education, Southeast University, China \\ ${ }^{2}$ Lecturer, Department of Civil Engineering, Strathclyde University, United Kingdom \\ ${ }^{3}$ Graduate Student, School of Civil Engineering, Southeast University, China \\ ${ }^{4}$ Professor, Key Lab. of C\&PC Structures of Ministry of Education, Southeast University, China \\ ${ }^{5}$ Associate Professor, School of Civil Engineering, Southeast University, China \\ *(Corresponding author: E-mail: yixiang.xu@strath.ac.uk(Yixiang Xu); seucivilfj@hotmail.com(Jian Feng))
}

Received: 29 April 2011; Revised: 21 July 2011; Accepted: 23 September 2011

\begin{abstract}
The use of cables as structural members has become very popular in spatial structures. The hybrid barrel vault is an attractive structural form in the design and construction of long-span transparent glass roof structures. These hybrid structures are very slender and lightweight, and hence sequential consideration in the structural behavior is needed. The mechanical characteristic, static and dynamic behaviors of the hybrid barrel vault are investigated in this paper. The effects of the structural parameters, such as rise-to-span ratios, cross-section areas of steel beams, areas and pre-stresses of cables, on the structural behavior have been studied in detail. Results show that cables do increase the structural stiffness of the hybrid barrel vault. The hybrid barrel vault with a good translucence is more efficient in load resistance than the general single-layer reticulated shell structure. Rise-to-span ratio is found to be an important factor influencing the structural behavior. The nodal displacement initially decreases with the increase of the height-to-span ratio and then increases afterwards. Given a specific height-to-span ratio, the increase of the beam section greatly reduces the nodal displacement and member forces and increases the natural frequency. It can also be found that it is not economical to improve the structural behavior by increasing the areas and pre-stresses of cables.
\end{abstract}

Keywords: Barrel vault, Cable, Anti-symmetrical load, Static analysis, Modal analysis

\section{INTRODUCTION}

In recent years, space structures have been broadly used all over the world. This has enhanced the rapid development of light weight structures, such as cable structures, membrane structures, and steel lattice structures. These structures are similar such that they are wide spans with a relatively small dead load [1]. Among these, barrel vaults having a form of a single-layer network of slender members are widely accepted as effective lightweight solutions to large span applications, because the barrel vaults carry loads mainly by normal forces. Recent applications have demonstrated that barrel vault structures covering clear spans of $17 \mathrm{~m}$ to $30 \mathrm{~m}$ have light self-weight of between 0.13 $\mathrm{kN} / \mathrm{m}^{2}$ and $0.20 \mathrm{kN} / \mathrm{m}^{2}$ [2]. Also, the static and dynamic behavior of barrel vaults has been studied by many researchers [2-7].

With the development of modern buildings, the appeal of glass roofs grows with their translucence. Barrel vaults with quadrangular mesh are one of the best candidates for transparent glass roofs. However, El-Sheikh [2, 3] pointed out that a vault with quadrangular mesh lacks integration between its segments, which is essential for a reliable structural action especially when the vault is acting as a beam or suffers local damage. Moreover, the vaults become most dependent on the joint rigidity. These serious shortfalls in structural performance outweigh the apparent benefits in reducing the number and length of members used and might limit these vaults to applications with short spans and light loadings. 
Cables are light and can provide well-defined transmission of forces. They can also been constructed to a structural system with a rational layout of members so as to make the best use of individual material properties [8]. Therefore, they are used in many hybrid string structures, such as beam string structures [9-11], and suspend-dome structures [12, 13]. To achieve high performance of the barrel vault with quadrangular mesh, a hybrid barrel vault roof is proposed [14-17], as shown in Figure 1. The single-layer steel trusses are diagonally stiffened by cables. Note the cables under compression will not become slack when the vault is pre-stressed before applying external loads. The hybrid barrel vault has a triangular mesh, which is a better structural configuration for barrel vaults [2, 3].

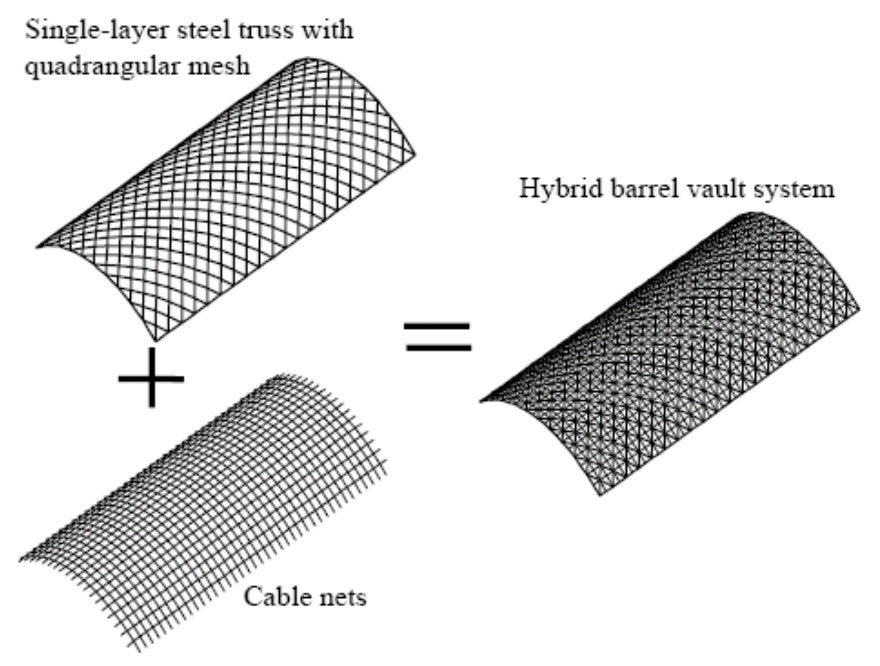

Figure 1. The Hybrid Barrel Vault System

Due to its attractive mechanical properties, the hybrid barrel vault has been widely used, e.g. the Word Trade Center Dresden and Atrium roof of Quartier 203 in Berlin [17], and the glass roof of New Guangzhou Railway station in China (as shown in Figure 2). The geometrical non-linear finite element analysis which considers imperfections of different shapes and scales was performed to study the stability of a hybrid barrel vault [1]. Harris et al. [18] described many innovations of creating the Downland Gridshell, a specialist museum workshop completed in the spring of 2002, such as multidisciplinary design, structural modeling, and the creation of new structural components, cladding, and construction processes. The principle of applying the cable pre-stress was investigated by Schlaich [16] based on a four-bar linkage diagonally stiffened by cables. Glymph et al. [19] studied the constructability of a hybrid shell using planar quadrilateral glass facets for the Jerusalem Museum of Tolerance project. They developed a simple but robust geometrical method for achieving the structure by incorporating the necessary geometrical principles into a computational parametric framework using the CATIA Version 5 system. The construction techniques and some case studies were concluded by Paoli [20]. He also investigated the development of high performance software and the use of new materials. Although the structural form is used in some projects, there is little research work reported about the structural characteristic of the hybrid vault barrel. 


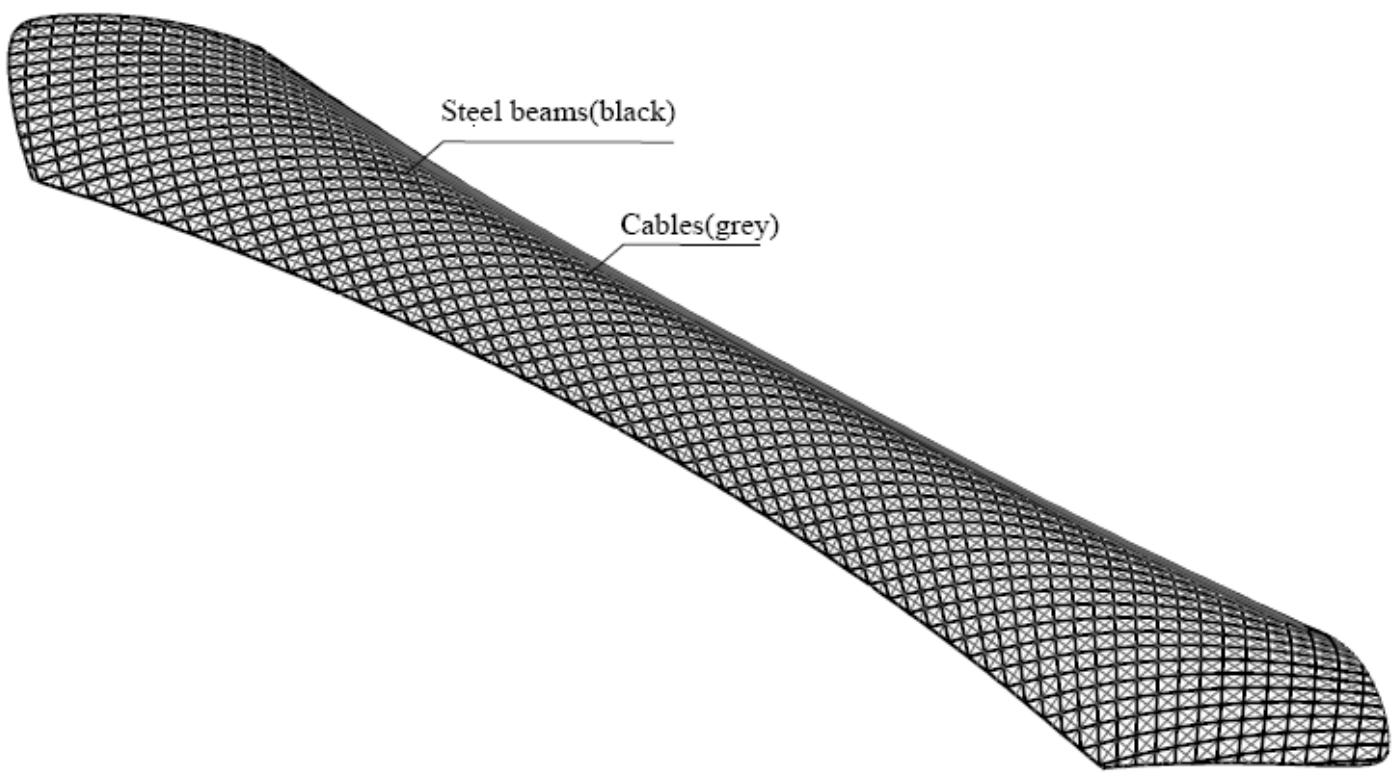

Figure 2. The Glass Roof of New Guangzhou Railway Station in China

This paper addresses several key issues of the hybrid barrel vault as shown in Figure 1. The mechanical characteristic of the hybrid structure is first investigated based on a frame structure stiffened by cables. Then a comparison of the static and dynamic behaviors between the hybrid barrel vault and the corresponding single-layer reticulated shell with quadrangular mesh is discussed in Section 3. Section 4 gives a parametric study of the static and dynamic behavior. Areas of steel bars and cables, pre-stresses of cables, rise-span ratios and different distribution of loads are considered. Section 5 draws some conclusions.

\section{MECHANICAL CHARACTERISTIC OF THE HYBRID STRUCTURE}

\subsection{The Basic Idea of Cable Pre-stress Force in the Hybrid System}

Unlike the tensegrity system, this hybrid system is stable before the cables are pre-stressed. Therefore, it does not require form-finding calculations. The pre-tensioned thin cables stiffen the quadrangular mesh barrel vault in two different ways. First, for a pin-connected four bar linkage, the cables transform the un-stiffened kinematic system into a statically determinate or indeterminate structure. For a single-layer rigid truss structure, the cables transform the system into a triangular meshed structure, which only allows in-plane flow of membrane forces resulting almost no bending stress in beams. The other method for cables to stiffen the hybrid system is that applying pre-tensions of cables transforms unfavorable compressive stresses into favorable tension stresses. Figure 3 shows a quadrangle of rigid beams with diagonal cables. One of diagonal cables will slack as it receives compression when the structure is under a lateral force. However, if cables have been pre-tensioned before applying the lateral load, neither cable will carry compression, and one cable carries a relatively higher tension leaving the other with a lower tension. It must be pointed out that the pre-stressed cables do not require a very high pre-stress, but ideally just large enough to prevent cables from slack when the structure is under service loads. It should be allowed that the cables be slack when the structure is in the ultimate state. 


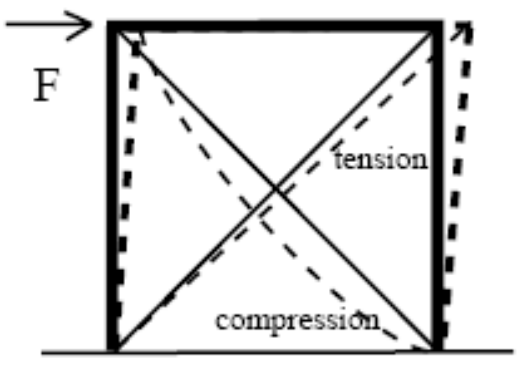

(a) without cable pretension

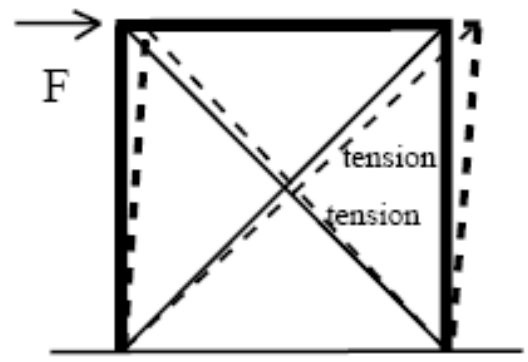

(b) with cable pretension

Figure 3. The Principle of Cable Pretension

\section{$2.2 \quad$ Effects of Cables}

Four load cases shown in Figure 4 are considered to investigate the effect of cables on the hybrid structure. Figure 5 shows the load-displacement curves for the braced and unbraced system. The load is plotted against the maximum displacement of a node. It is clear from the figure that the structural stiffness is rapidly reduced in the absence of pre-stressed cables for all load cases.
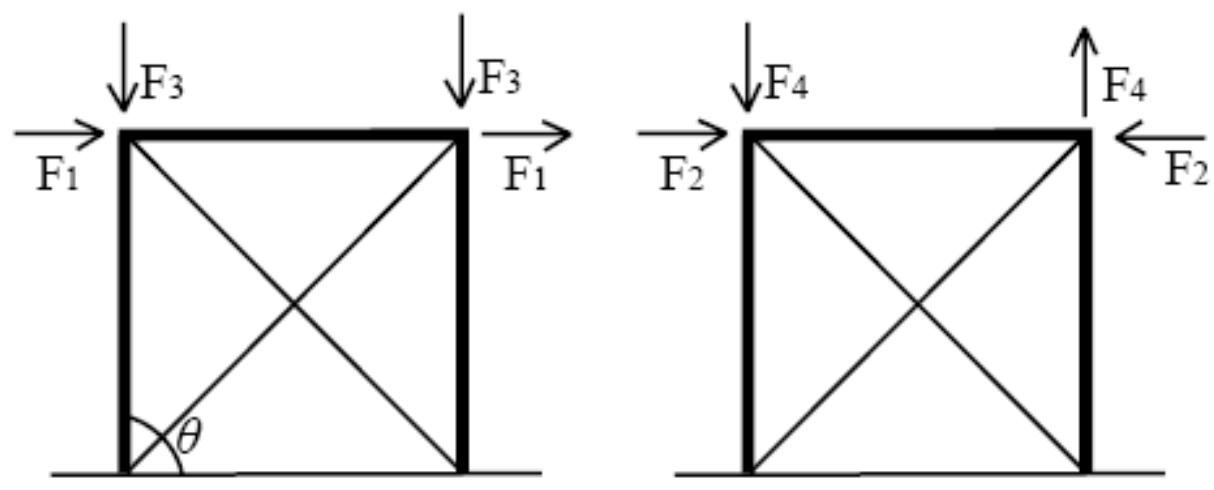

Figure 4. Four Different Load Cases

The load-displacement curves for the structure with different included angles are shown in Figure 6. The included angle $\theta$ is defined as the angle between two adjacent elements as shown in Figure 4 . The included angle $\theta$ shown in Figure 6 corresponds to $15^{\circ}, 30^{\circ}, 45^{\circ}, 60^{\circ}, 75^{\circ}$ and $90^{\circ}$, respectively. It can be seen from the figure that the stiffness of the structure with cables is higher than the structure without cables. Furthermore, the structural stiffness of an unbraced structure decreases with an increase of the included angle. However, for a braced structure, the structural stiffness reduces initially and increases afterward with the increase of included angles.

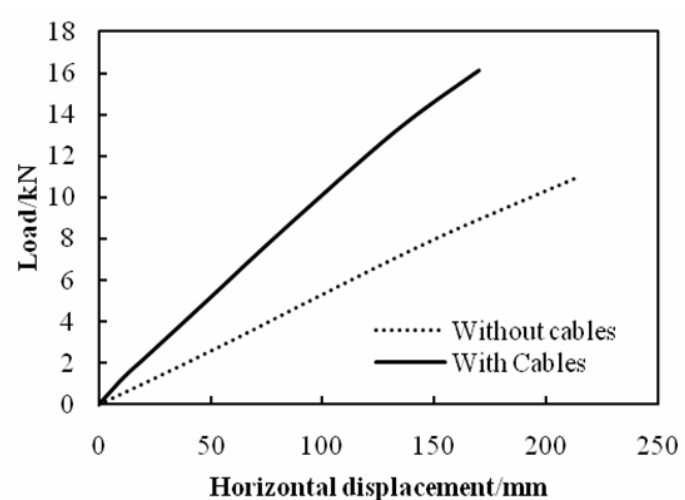

(a) Load $F_{1}$

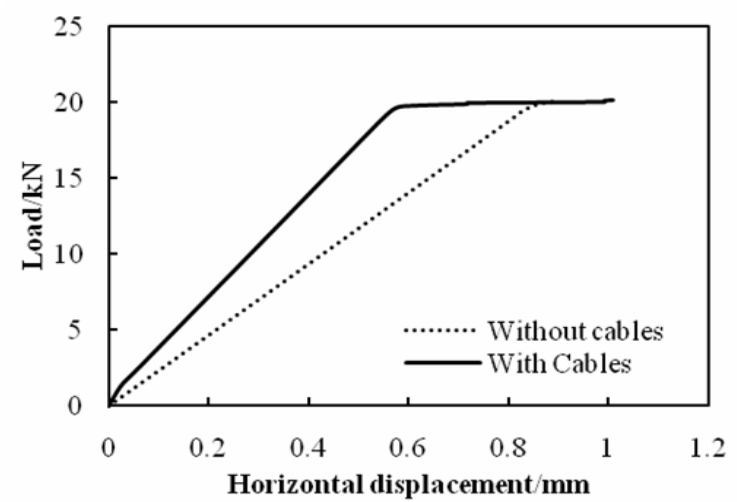

(b) Load $\mathrm{F}_{2}$ 


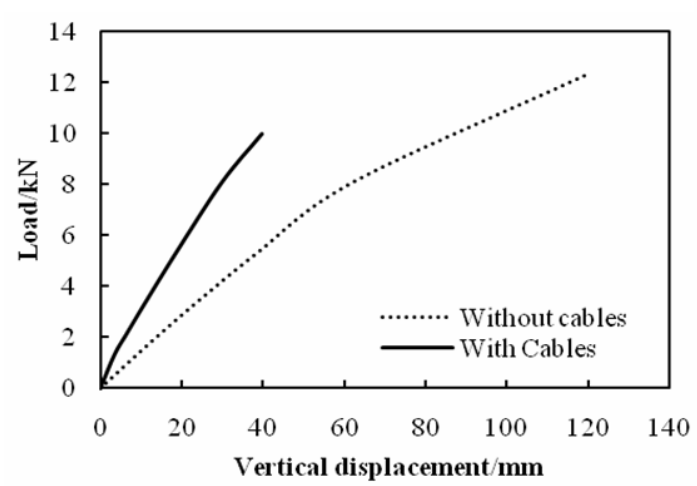

(c) Load $\mathrm{F}_{3}$

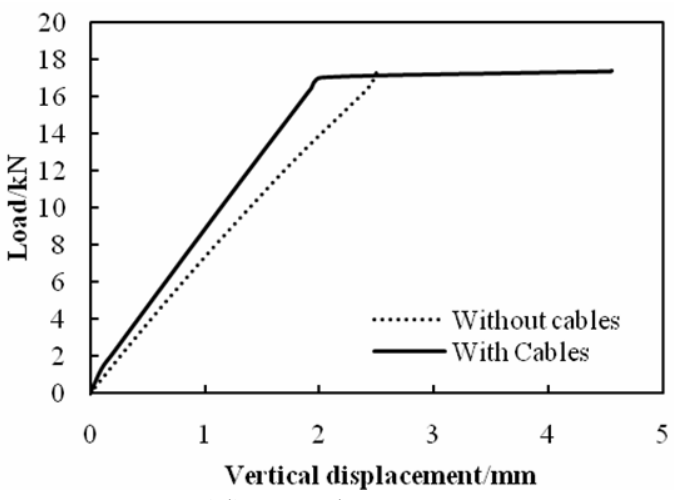

(d) Load F 4

Figure 5. Load-displacement Curves for Different Load Cases

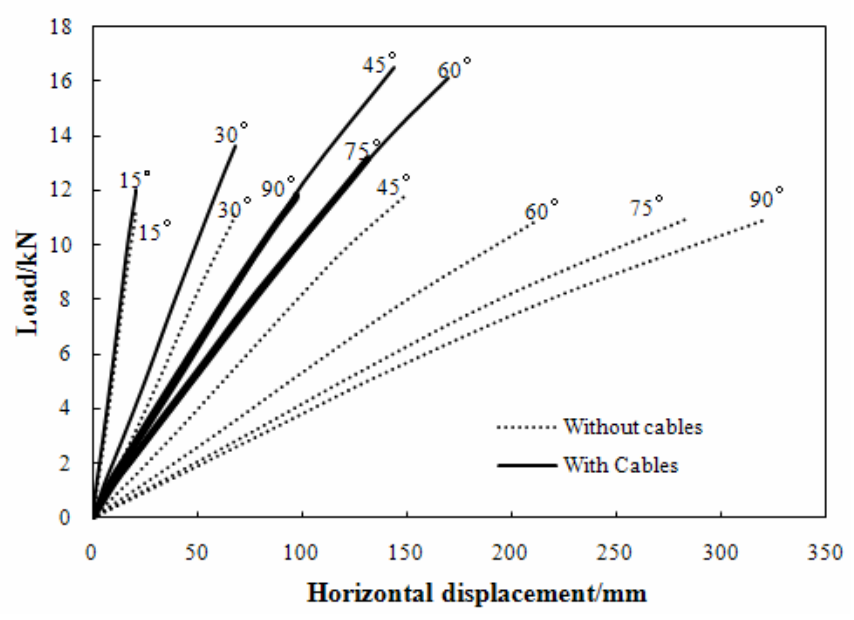

Figure 6. Load-displacement Curves for included Angles

\section{STRUCTURAL BEHAVIOR OF A HYBRID VAULT BARREL}

\subsection{The Design Model}

The design example used in this study is shown in Figure 7. The span and rise of the barrel vault structure are $20 \mathrm{~m}$ and $5.2 \mathrm{~m}$, respectively (making the rise-span ratio 0.26). All nodes at the perimeter are hinged to the fixed support. Many types of connections are commonly used in space structure constructions such as welded hollow ball connections and bolt ball connections [13]. The welded hollow ball connection is adopted in this study, which is assumed to be rigid. The principal members of the single-layer steel trusses are made of steel with a Young's modulus of $206 \mathrm{GPa}$, and the cross-section is $120 \mathrm{~mm} \times 60 \mathrm{~mm} \times 4 \mathrm{~mm}$ (height $\times$ width $\times$ thickness). The yield strength of the steel beam is $345 \mathrm{MPa}$. The diameter of cables is $10 \mathrm{~mm}$ and the Young's modulus is $180 \mathrm{GPa}$. The initial stress of cables is $100 \mathrm{MPa}$. 


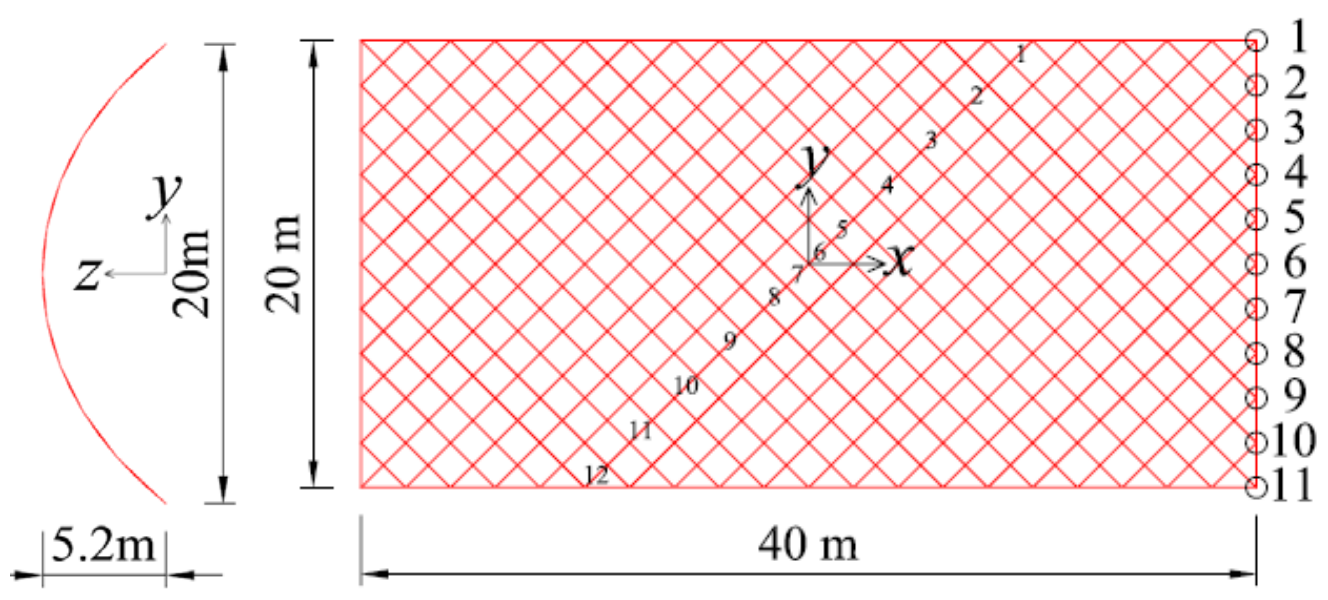

Figure 7. The Design Model of the Hybrid Barrel Vault with Typical Node and Element Numbers (Shown Without Cables)

The symmetrical load case $g+s$ (dead load +snow load) has been taken into account in all computations. The dead load $g$ consists of a self-weight of $0.5 \mathrm{kN} / \mathrm{m}^{2}$ including all beams and cables. The snow load is applied to the top surface of the structure in the vertical direction with a magnitude of $0.5 \mathrm{kN} / \mathrm{m}^{2}$.

The Finite Element Analysis software ANSYS is employed in all structural analyses that have taken into account the geometrical non-linearity. Tension-only element LINK10 is used to model cables and BEAM 189 is chosen to simulate steel beams. Due to the pre-stresses, all the cables remain in tension throughout the analysis.

\subsection{Comparison between the Hybrid Barrel Vault and the Single-layer Lattice Structure}

Static and dynamic analyses are carried out for the hybrid barrel vault structure and the corresponding single-layer lattice structure. The latter structure is formed by removing all the cables in the hybrid structure of the same dimension. By comparing the simulated results, one can evaluate the relative efficiency of those two structures.

\subsubsection{Static analysis}

The construction process of a pre-stressed space structure can be divided into three configurations: the zero state, the initial state and the loaded state. The structure in zero state is not pre-stressed. The initial state, also called pre-stressed state, is corresponding to the configuration under self-weight and initial forces. The loaded state is the shape under external actions.

In order to study the behavior of the hybrid structure under external loads, an analysis is carried out in three phases. In Phase I, only initial cable forces are applied to the finite element model to calculate the structural deformation and resultant forces of all members without any external load. In Phase II, based on a pristine unstressed numerical model, simulation is carried out to calculate the deformation and forces of members again after applying both the initial stresses and external loads. In Phase III, the overall structural responses of the hybrid barrel vault under external loads only can then be obtained by subtracting the results of Phase 1 from Phase 2. With the help of this approach, it is easy to identify individual member stress and nodal displacement due to external load only. 
The typical nodes and elements of the barrel vault structure are shown in Figure 7. The vertical displacements for the typical nodes of the two structures are given in Figure 8. The vertical deflections of the single-layer lattice structure are much larger than those of the hybrid barrel vault structure. In general, the nodal displacements of the hybrid structure are less than $60 \%$ of the corresponding single-layer lattice structure.

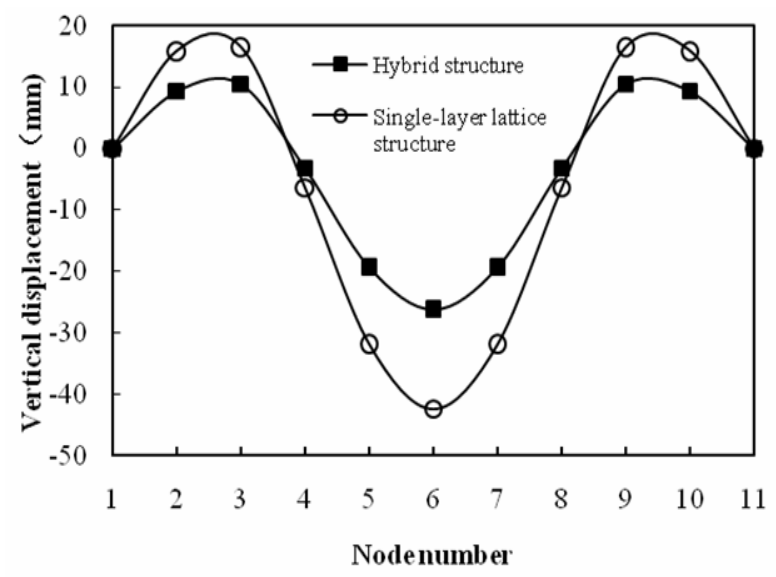

Figure 8. Vertical Displacement for Typical Nodes

In addition to the deformation, Figure 9 shows the cables also greatly reduce axial forces. It is clear from the figure that the magnitudes of the axial forces in the hybrid structure are much smaller than those of the corresponding single-layer lattice structure, especially for the members adjacent to the center of the span. With the help of the cables, the axial force of element 6, as labeled in Figure 7, decreases from $11.24 \mathrm{kN}$ to $10.23 \mathrm{kN}$ in the presence of an external load.

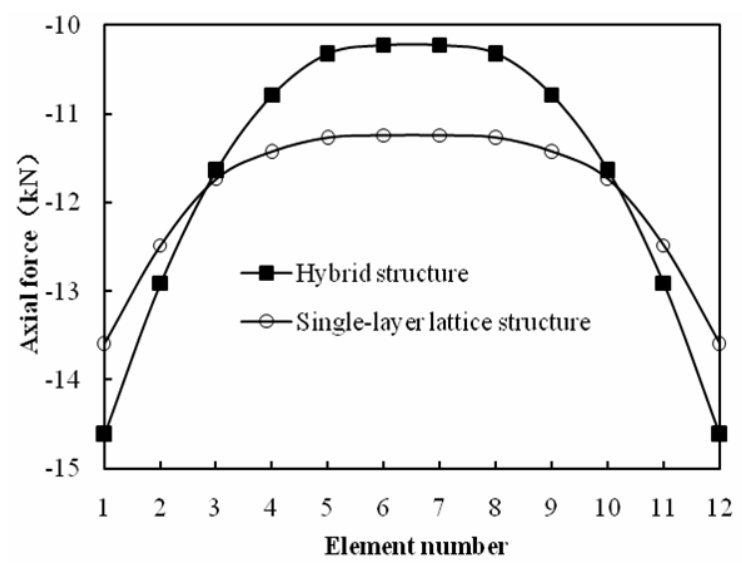

Figure 9. Axial Forces for Typical Members

\subsubsection{Dynamic analysis}

Modal analyses of two barrel vault structures are carried out, and the natural frequencies of the first thirty modes are plotted in Figure 10. For the first three natural frequencies, it shows little difference between two structures. However, the hybrid barrel vault structure has higher natural frequencies from the fourth mode because the pre-stressed cables result in a higher stiffness of the structure. Hence, the natural frequencies of the system increase. 


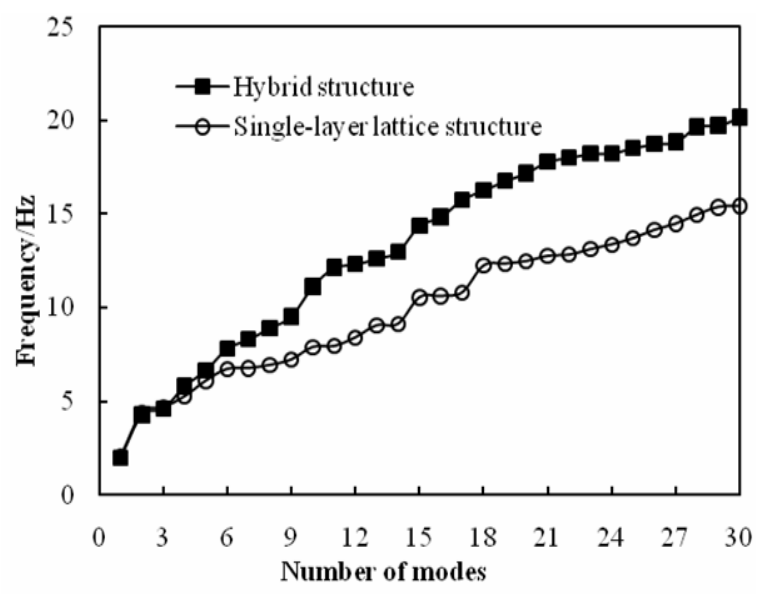

Figure 10. The Natural Frequencies of the First 30 Modes

The criterion of a good design should include a high stiffness of the overall structure thus reducing nodal displacement etc. when fully loaded as well as a higher natural frequency to minimize vibration effects. The results of the static and dynamic analyses have shown that the hybrid structure is a more efficient structural form compared with the single-layer lattice system.

\section{PARAMETRIC STUDY OF STRUCTURAL CHARACTERISTICS}

The effects of rise-to-span ratios, cross-sections of steel beams, areas of cables, initial cable stresses and anti-symmetric loads on the static and dynamic behavior of the hybrid barrel vault roof are studied.

\subsection{Influence of Rise-to-span Ratio}

The rise-to-span ratio is an important factor that affects the structural behavior of hybrid systems. By changing the rise of the primary model in 5 cases, five hybrid barrel vault models can be constructed. The axial forces of typical members and the vertical nodal deformations are calculated and shown in Figure 11. For the axial forces of typical members, Figure 11 shows that the higher the rise-to-span ratios, the lower the axial forces will be. However, a similar trend cannot be found for the nodal vertical displacements. If the rise-span ratio is smaller than 0.2 , an increase in rise-to-span ratio will result in a decrease in nodal displacements. If the rise-to-span ratio is greater than 0.2 , the deformation will increase with the rise-to-span.

Apart from the concerns of the static behavior, changes in the dynamic behavior of hybrid system due to different rise-to-span ratios have also been studied. Modal analyses of the five hybrid structures have been carried out, and the natural frequencies of the first three modes are summarized in Table 1. It shows that when the rise-to-span ratio increases, the natural frequencies of the hybrid barrel vault will decrease.

It can be concluded that there exists an optimal value of rise-to-span ratio for a specific hybrid barrel vault roof to be an effective long-span structural system, because an either too large or too small rise-to-ratio will induce larger nodal displacements. The optimal value of the ratio is found to be between 0.2 and 0.26 from the simulation study presented in this paper. 


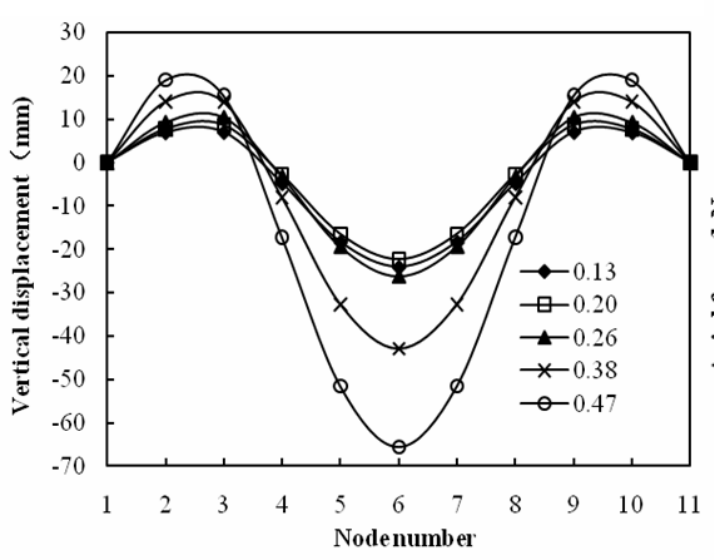

(a) Nodal displacement

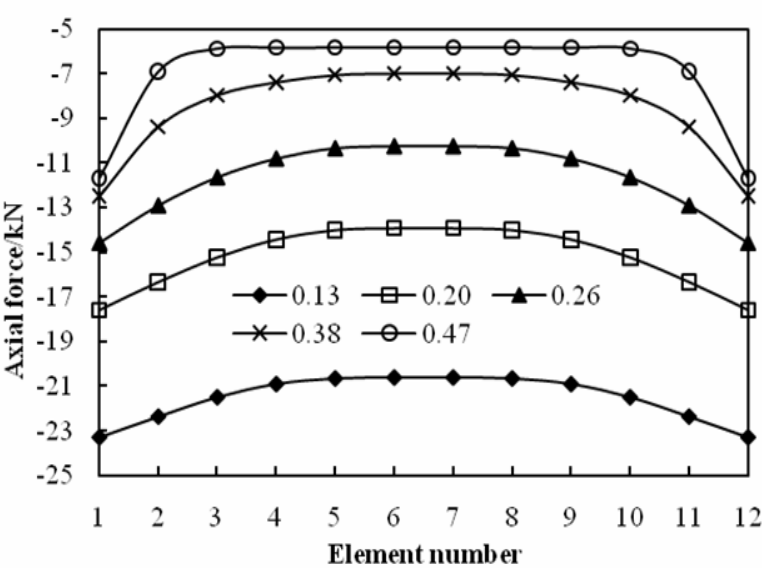

(b) Axial force of members

Figure 11. Effects of Rise-to-span Ratio on the Structural Behavior

Table 1. The Natural Frequencies (Hz) with Different Rise-to-span Ratios

\begin{tabular}{cccccc}
\hline Rise-to-span ratio & 0.13 & 0.2 & 0.26 & 0.38 & 0.47 \\
\hline First mode & 2.2751 & 2.1974 & 1.9923 & 1.5451 & 1.2481 \\
Second mode & 4.7335 & 4.6033 & 4.2915 & 3.5539 & 3.0076 \\
Third mode & 5.1347 & 4.9729 & 4.6135 & 3.7898 & 3.1899 \\
\hline
\end{tabular}

\subsection{Influence of Cross-sections of Steel Beams}

A series of analyses have been carried out using the example structure with different cross-sections to study the effect of rigidity of beams on structural behavior. The nodal displacements and axial forces of typical elements with respect to different cross-sections of steel beams are shown in Figure 12 where four cross-sections, $110 \mathrm{~mm} \times 55 \mathrm{~mm} \times 3 \mathrm{~mm}, 120 \mathrm{~mm} \times 60 \mathrm{~mm} \times 4 \mathrm{~mm}, 150$ $\mathrm{mm} \times 75 \mathrm{~mm} \times 4 \mathrm{~mm}, 170 \mathrm{~mm} \times 80 \mathrm{~mm} \times 5 \mathrm{~mm}$, are considered in this study.

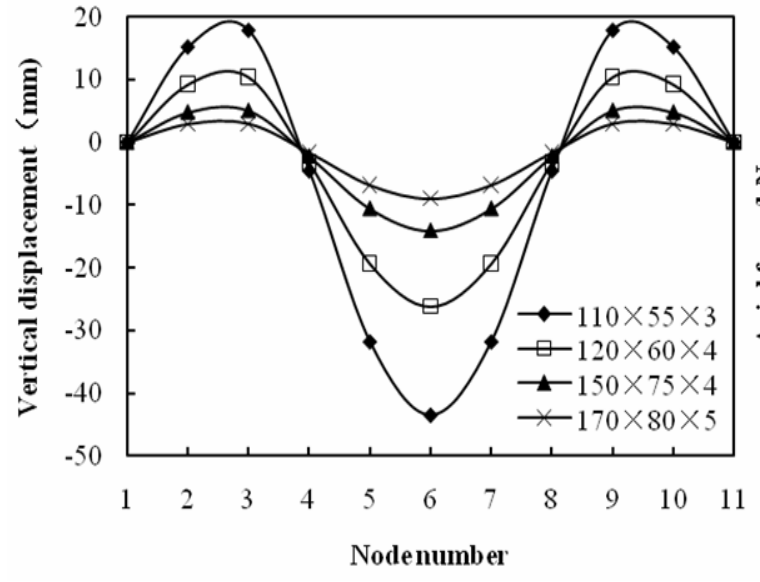

(a) Nodal displacement

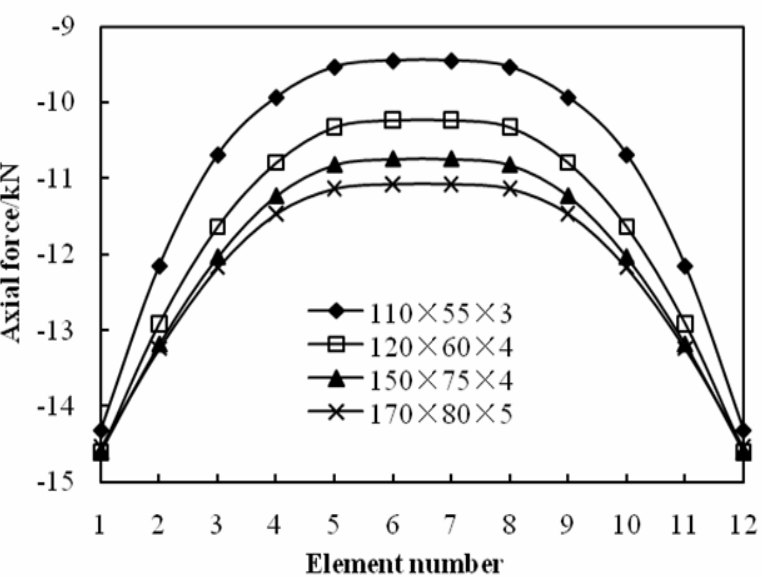

(b) Axial force of members

Figure 12. Effects of Cross-section of Steel Beams on the Structural Behavior

It can be seen that the vertical displacement reduces significantly when the structure has a larger beam cross-section. When the cross-section increases from $110 \mathrm{~mm} \times 55 \mathrm{~mm} \times 3 \mathrm{~mm}$ to $170 \mathrm{~mm} \times$ $80 \mathrm{~mm} \times 5 \mathrm{~mm}$, the maximal nodal vertical displacement decreases from $-43.4 \mathrm{~mm}$ to $-8.9 \mathrm{~mm}$ under an external load only. It can also be found that the axial forces of members also decrease with the increase of the beam cross-section. However, the influence of beam section on axial forces of members is limited. 
The natural frequencies of the first three modes for the hybrid structure with different beam sections are given in Table 2. It shows that the natural frequencies increase significantly with the increase of the beam section. It can be concluded that the beam section is very important for stiffening the structure.

Table 2. The Natural Frequencies (Hz) with Different Cross-sections of Steel Beams

\begin{tabular}{ccccc}
\hline Cross-section of steel beams $/ \mathrm{mm}$ & $110 \times 55 \times 3$ & $120 \times 60 \times 4$ & $150 \times 75 \times 4$ & $170 \times 80 \times 5$ \\
\hline First mode & 1.6589 & 1.9923 & 2.681 & 3.0752 \\
Second mode & 3.7407 & 4.2915 & 5.6059 & 6.3571 \\
Third mode & 4.044 & 4.6135 & 5.997 & 6.7856 \\
\hline
\end{tabular}

\subsection{Influence of Cables}

The pre-stresses and areas of cables are also important factors that affect the static and dynamic behavior of the hybrid barrel vault.

\subsubsection{Cable area}

The typical nodal displacements and axial forces of typical elements under external loads, corresponding to different diameters of cables at a specified pre-stress of $100 \mathrm{MPa}$ are shown in Figure 13. The diameter of cables corresponds to $8 \mathrm{~mm}, 10 \mathrm{~mm}, 12 \mathrm{~mm}, 15 \mathrm{~mm}$ and $20 \mathrm{~mm}$ in Figure 13, respectively. It can be seen that the influence of cable areas on vertical displacements and axial forces of typical members is very limited. When the area of cables is multiplied by 6.25 (where the diameter of cables increases from $8 \mathrm{~mm}$ to $20 \mathrm{~mm}$ ), the vertical displacement of node 6 and the axial forces of element 6 decrease by about 30 percent.

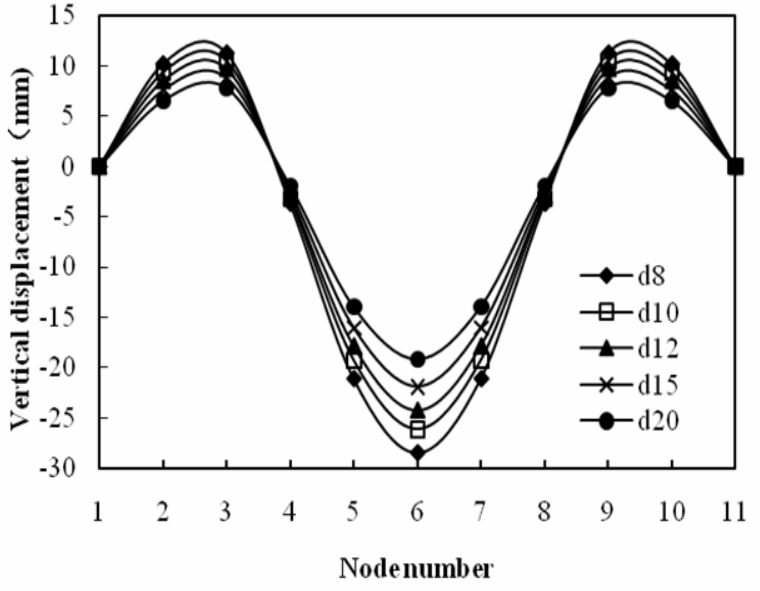

(a) Nodal displacement

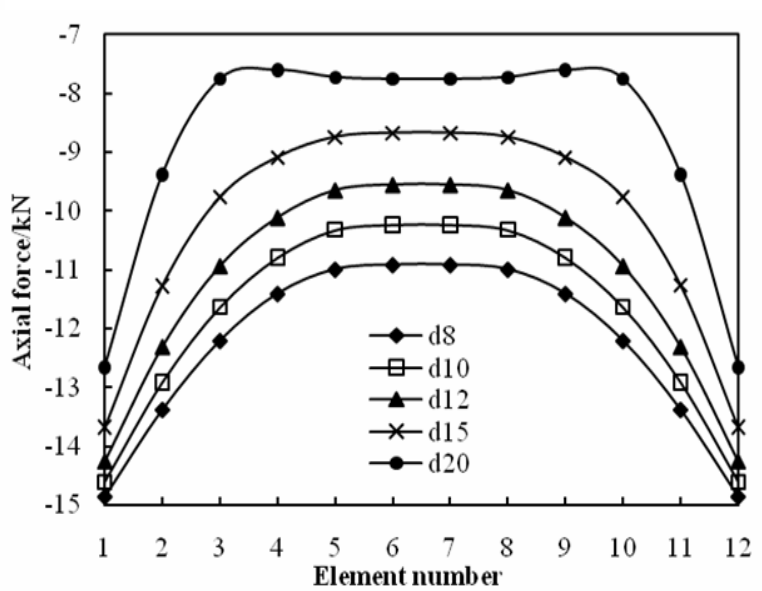

(b) Axial force of members

Figure 13. Effects of Area of Cables on the Structural Behavior

The natural frequencies of the hybrid structure with different areas of cables are given in Table 3. It can be found that the natural frequencies decrease slightly with the increase of the cable area. This is actually expected since a higher weight will generally result in a lower natural frequency.

Table 3. The Natural Frequencies (Hz) with Different Areas of Cables

\begin{tabular}{cccccc}
\hline Diameter of cables $/ \mathrm{mm}$ & 8 & 10 & 12 & 15 & 20 \\
\hline First mode & 2.0137 & 1.9923 & 1.9666 & 1.9207 & 1.8297 \\
Second mode & 4.3352 & 4.2915 & 4.2385 & 4.1438 & 3.9552 \\
Third mode & 4.6519 & 4.6135 & 4.5646 & 4.4742 & 4.2881 \\
\hline
\end{tabular}




\subsubsection{Cable pre-stress}

Different levels of initial stresses are set to $0 \mathrm{MPa}, 50 \mathrm{MPa}, 100 \mathrm{MPa}, 150 \mathrm{MPa}, 200 \mathrm{MPa}$ and 300 $\mathrm{MPa}$, respectively. The typical nodal displacements and axial forces of typical elements against the specified cable pre-stresses are shown in Figure 14. It should be noted that the results illustrated in Figure 14 are obtained from Phase III of the method described in Section 3.2.1. It shows that the differences in vertical nodal displacements among the hybrid structures due to different pre-stress values of the cable are very small. However, the model with zero initial stress gives highest nodal displacements. It should be noted that the cable prestress will have small effect when it is between $0 \mathrm{MPa}$ and $50 \mathrm{MPa}$, so there is a step change between these two curves. However, when the cable prestress is $50 \mathrm{MPa}$, the axial force of the cable is very small, so the smaller cable prestresses, such as $10 \mathrm{MPa}$, $20 \mathrm{MPa}$, were not considered by the authors. Moreover, when the cable prestress is under $50 \mathrm{MPa}$, the cable may be slack under temperature loads.

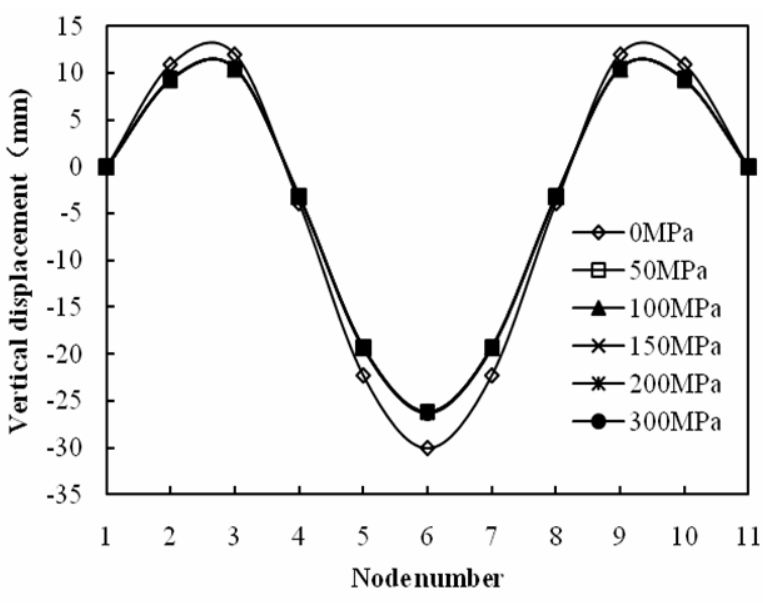

(a) Nodal displacement

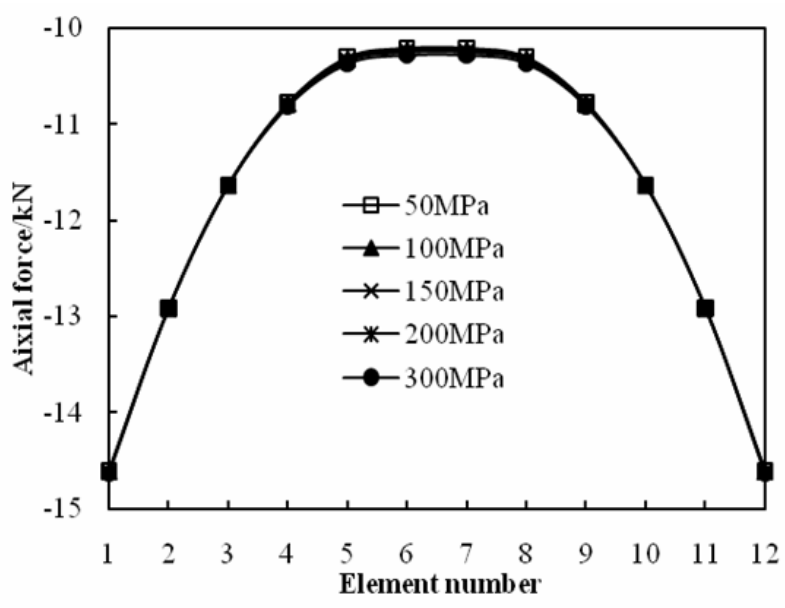

(b) Axial force of members

Figure 14. Effects of Cable Pre-stress on the Structural Behavior

Table 4. The Natural Frequencies (Hz) with Different Cable Pre-stress

\begin{tabular}{cccccc}
\hline Cable pre-stress/MPa & 50 & 100 & 150 & 200 & 300 \\
\hline First mode & 1.9941 & 1.9923 & 1.9888 & 1.9853 & 1.9783 \\
Second mode & 4.294 & 4.2915 & 4.2846 & 4.2776 & 4.2637 \\
Third mode & 4.6079 & 4.6135 & 4.6085 & 4.6035 & 4.5935 \\
\hline
\end{tabular}

It can also be seen from Figure 14 that the increase of cable pre-stress leads to a very slight rise of axial forces of typical elements. However, from the method described in Section 3.2.1, it should be noted that the axial forces given in Figure 14 are only resulted from an external load. If both the pre-stress and external loads are considered, a higher pre-stress will result in a higher member force. Thus, it is not an economical way to improve the structural behavior simply by increasing the level of pre-stress only.

Modal analyses of the hybrid structure with different areas of cables have been carried out, and the natural frequencies of the first three modes are given in Table 4. It can be found that differences in natural frequencies among the five cases are very small. 


\subsection{Influence of Anti-symmetrical Load}

Another factor to be considered in this study is the anti-symmetrical load. One type of anti-symmetrical load is the half-span load which can be induced during construction or by snow. The anti-symmetrical load case $g+s / 2$ (dead load+ snow load on half span of the structure) is considered in this study. The symmetrical load case is denoted as Load 1, and the anti-symmetrical load case Load 2.

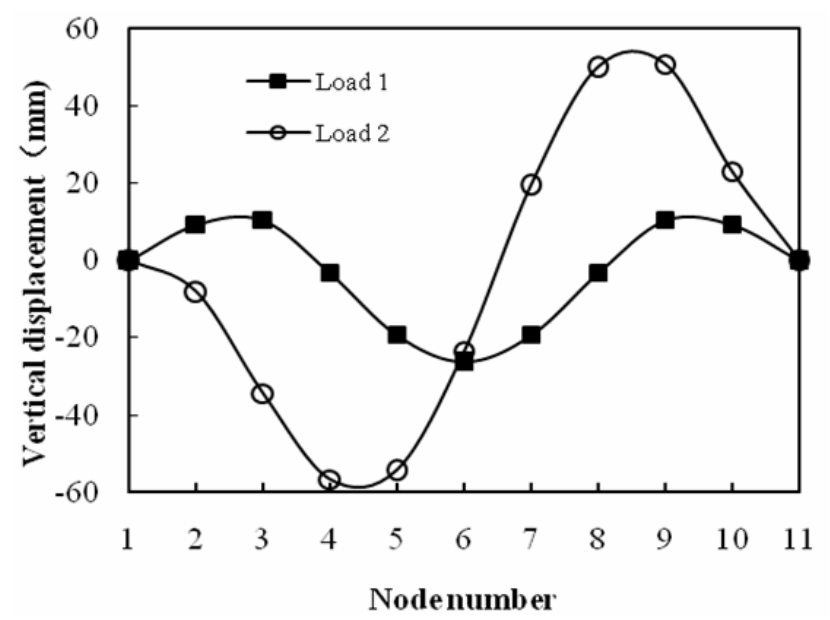

Figure 15. Effects of Anti-symmetrical Loads on the Nodal Vertical Displacement

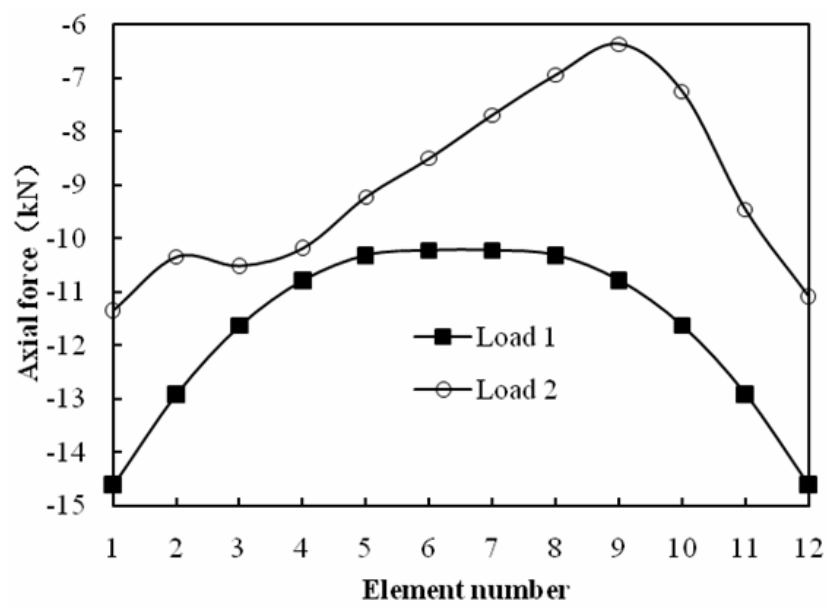

Figure 16. Effects of Anti-symmetrical Loads on the Axial Forces of Elements

The vertical nodal displacements of the hybrid structure under two load cases are given in Figure 15. It shows the anti-symmetrical distribution of load imposes very large effect on the vertical nodal displacement. The vertical displacements under Load 2 are larger than Load 1, and the deformed shapes are different as shown in Figure 15. Figure 16 shows the axial forces of elements under both symmetrical and anti-symmetrical load cases. It can be seen that the axial forces are smaller than those from full-span load, and are unevenly distributed along the span.

\section{CONCLUSIONS}

The mechanical characteristic of the hybrid structure was investigated based on a quadrangle of slats with cross cables. Comprehensive static and dynamic analyses were carried out on the hybrid barrel vault and the single-layer reticulated shell. Then a numerical parametric analysis of the hybrid structure was performed. Based on the results, the following conclusions are drawn: 
1. Cables will increase the structural stiffness of the four-beam element. Moreover, the structural stiffness is dependent on the included angle $\theta$. It initially decreases with the increase of the include angle and then increases afterwards.

2. Introducing cables, causes the hybrid system, when compared with the single-layer reticulated shell, to acquire smaller structural deformations, lower member forces, and higher natural frequencies.

3. Hybrid barrel vaults have high stiffness given the rise-to-span range of 0.20-0.26 and consequently possess good dynamic performance. For different loading conditions, the optimal rise-to-span ratio of hybrid barrel vaults may be different from above ratios.

4. Cross-sections are one of the most important factors influencing the static and dynamic behavior of the hybrid structure. In order to achieve excellent performance, it is very important to stiffen the structure, and thus reduce nodal displacements and member forces, yielding higher natural frequencies. However, adjusting both the areas and pre-stress of cables are not effective method for improving the structural behavior.

5. The static behavior of a hybrid barrel vault is sensitive to the anti-symmetrical distribution of load. The anti-symmetric load increases the nodal displacements and reduces the axial forces of members.

\section{ACKNOWLEDGEMENTS}

The work presented in this article was supported by the National Natural Science Foundation of China (Grant No. 50478075), Jiangsu “Six Top Talent” Program of China (Grant No.07-F-008), a Project Funded by the Priority Academic Program Development of Jiangsu Higher Education Institutions and Scientific Research Foundation of Graduate School of Southeast University (Grant No. YBJJ0817). The first author would like to thank the China Scholarship Council for sponsoring his stay at the California Institute of Technology.

\section{REFERENCES}

[1] Bulenda, T. and Knippers, J., "Stability of Gird Shells”, Computers \& Structures, 2001, Vol. 79, pp. 1161-1174.

[2] El-Sheikh, A., "Configurations of Single-Layer Barrel Vaults”, Advances in Structural Engineering, 2001, Vol. 4, No. 2, pp. 53-64.

[3] El-Sheikh, A., "Performance of Single-layer Barrel Vaults with Different Configurations", International Journal of Space Structures, 2001, Vol. 16, No. 2, pp. 111-123.

[4] El-Sheikh, A., "Effect of Geometric Imperfections on Single-layer Barrel Vaults", International Journal of Space Structures, 2002, Vol. 17, No. 4, pp. 271-283.

[5] Hanaor, A., "Design and Behaviour of Reticulated Spatial Structural Systems”, International Journal of Space Structures, 1995, Vol. 10, No. 3, pp. 139-149.

[6] Makowski, Z.S., “Analysis, Design and Construction of Braced Barrel Vaults”, Elsevier Applied Science Publishers, London, 1985.

[7] Manning, M.W. and Dallard, P., "Lattice Shells: Recent Experiences", The Structural Engineer, 1998, Vol. 76, No. 2, pp. 105-110. 
[8] Hosozawa, O., Shimamura, K. and Mizutani, T., “The Role of Cables in Large Span Spatial Structures: Introduction of Recent Space Structures with Cables in Japan”, Engineering Structures, 1999, Vol. 21, pp. 795-804.

[9] Saitoh, M. and Okada, A., "The Role of String in Hybrid String Structures”, Engineering Structures, 1999, Vol. 21, pp. 756-769.

[10] Xue, W. and Liu, S., "Studies on a Large-Span Beam String Pipeline Crossing”, Journal of Structural Engineering, 2008, Vol. 134, No. 10, pp. 1657-1667.

[11] Xue, W. and Liu, S., "Design Optimization and Experimental Study on Beam String Structures”, Journal of Constructional Steel Research, 2009, Vol. 65, pp. 70-80.

[12] Kitipornchai, S., Kang, W., Lam, H.F. and Albermani, F., "Factors Affecting the Design and Construction of Lamella Suspen-dome Systems", Journal of Constructional Steel Research, 2005, Vol. 61, pp. 764-785.

[13] Kang, W., Chen, Z., Lam, H.F. and Zuo, C., "Analysis and Design of the General and Outmost-ring Stiffened Suspen-dome Structures”, Engineering Structures, 2003, Vol. 25, pp. 1685-1695.

[14] Schlaich, J. and Schober, H., “Glass-covered Gird-shells”, Structural Engineering International, 1996, Vol. 6, pp. 88-90.

[15] Schlaich, J. and Schober, H., "Glass Roof for the Hippo House at the Berlin Zoo", Structural Engineering International, 1997, Vol. 7, pp. 252-254.

[16] Schlaich, J., "Concept Design of Light Structures”, Journal of the International Association for Shell and Spatial Structures, 2004, Vol. 45, pp. 157-168.

[17] Schlaich, J. and Schober, H., "Recent Glass Roofs", Journal of the International Association for Shell and Spatial Structures, 1999, Vol. 40, pp. 193-205.

[18] Harris, R., Romer, J., Kelly, O. and Johnson, S., "Design and Construction of the Downland Gridshell”, Building Research \& Information, 2003, Vol. 31, No. 6, pp. 427-454.

[19] Glymph, J., Shelden, D., Ceccato, C., Mussel, J. and Schober, H., “A Parametric Strategy for Free-form Glass Structures Using Quadrilateral Planar Facets”, Automation in Construction, 2004, Vol. 13, pp. 187-202.

[20] Paoli, C., "Past and Future of Grid Shell Structures”, Massachusetts Institute of Technology, 2007. 